\title{
Um Psicanalista Fazendo Outra Coisa: Reflexões Sobre Setting na Psicanálise Extramuros
}

An Analyst Doing Something Else: Reflections on Setting and Outside-Wall Clinic

Un Psicoanalista Haciendo Otra Cosa:

Reflexiones Acerca de Setting en el Psicoanálisis Extramuros

\section{Maria Vitória Campos Mamede Maia Universidade Federal do Rio de Janeiro \\ Nadja Nara Barbosa Pinheiro Universidade Federal do Paraná}


Resumo: O texto propõe uma reflexão sobre a questão do setting no desenvolvimento de atendimentos psicanalíticos na clínica dita extramuros. Apresenta dois exemplos clínicos conduzidos pelas autoras em contextos não convencionais, a clínica-escola de uma universidade e o ambulatório de psicologia de um hospital geral, para sustentar suas hipóteses sobre o entendimento de setting a partir de uma vertente ética, e não técnica, isto é, para as autoras, setting se refere ao campo teórico que sustenta a condução da clínica, e não ao lugar em que o trabalho transcorre. Em seguida, os ensinamentos de Freud e de Winnicott sobre a questão são tomados como fundamento teórico. Nesse sentido, Freud sustenta uma flexibilidade técnica em contraposição ao rigor teórico. Por sua vez, Winnicott afirma que há uma adaptação ativa do analista às necessidades de seu paciente na condução da clínica. Esses ensinamentos são base para um questionamento radical sobre a própria expressão extramuros, ou seja, em se tratando de psicanálise, há muros?

Palavras-chave: Clínica psicanalítica. Setting (Psicanálise). Manejo clínico. Psicanálise

Abstract: The present text proposes a reflection on the idea of setting in the conduction of psychoanalytical processes developed in non-conventional environments. It presents two clinical samples conducted by the authors in this kind of environment, a clinical-school of a university and an ambulatory of psychology in a general hospital, to sustain their hypotheses about setting taking this notion from a theoretical frame and not from a technical frame. Then, it makes use of Freud's and Winnicott's teaching as fundamental references for these matters. First of all, Freud supports a flexibility on the technical field in opposition to a rigor in the theoretical field. On his turn, Winnicott sustains that the analyst should make an active adaptation to his patients needs. Those teachings are taken as basis to question the expression outside-wall referring to the psychoanalytical clinic, such as: in reference to psychoanalysis, are there walls?

Keywords: Psychoanalytical clinic. Setting (Psychoanalysis). Clinical management. Psychoanalysis.

Resumen: El texto propone una reflexión acerca de la cuestión del setting en el desarrollo de atenciones psicoanalíticas en la clínica llamada extramuros. Presenta dos ejemplos clínicos conducidos por las autoras en contextos no convencionales, la clínica-escuela de una universidad y el ambulatorio de psicología de un hospital general con el fin de sostener sus hipótesis acerca del entendimiento de setting a partir de una vertiente ética, y no técnica, es decir, para las autoras, setting se refiere al campo teórico que sostiene la conducción de la clínica, y no al sitio en el cual el trabajo es llevado a cabo. Enseguida, las enseñanzas de Freud y de Winnicott acerca de la cuestión son tomadas como fundamento teórico. En ese sentido, Freud sostiene una flexibilidad técnica en contraposición al rigor teórico. A su vez, Winnicot afirma que existe una adaptación activa del analista a las necesidades de su paciente en la conducción de la clínica. Esas enseñanzas sirven de base para un cuestionamiento radical acerca de la propia expresión extramuros, es decir, cuando se trata de psicoanálisis, ¿existen muros?

Palabras clave: Clínica psicoanalítica. Setting Psicoanálisis). Manejo Clínico. Psicoanálisis.

Podemos considerar que o trabalho clínico da psicanálise possua dois momentos distintos, mas interligados. Propomos, aqui, considerá-lo uma viagem. Há um momento dedicado a uma série de preparativos, como a escolha do destino, a compra das passagens, a reserva dos hotéis, o planejamento dos lugares a serem visitados, etc.

Todos esses preparativos fazem parte da viagem, a antecedem, a preparam e, sem eles, a viagem não ocorreria, mas não são, ainda, a viagem propriamente dita! Essa, sem os preparativos, não aconteceria, mas deles se diferencia na hora do embarque, instante a partir do qual a experiência, a vivência, a travessia se iniciam e se inauguram, sempre singulares, sempre inesperadas, nunca antecipáveis em suas dificuldades e conquistas.

Assim também ocorre na clínica; há momentos preparatórios que antecedem o trabalho propriamente dito e criam suas condições de possibilidade. Se o paciente quer, se ele tem condições, se ele precisa embarcar e se vai nos convidar para sermos seu acompanhante na viagem... só o tempo nos dirá.

A metáfora acima utilizada não é originalmente nossa, mas de Freud. Ele a utilizou na apresentação de um belíssimo 
1 Por questões de sigilo, os nomes dos pacientes, assim como algumas situações descritas, foram modificados. Por questões éticas, os locais em que transcorreram os atendimentos são universitários, ou seja, centros de estudo e pesquisa em que os pacientes assinam termos de consentimento de que seus casos podem ser utilizados em estudos científicos. caso clínico por ele conduzido do qual gostaríamos de destacar alguns pontos que acreditamos importantes para nossas reflexões sobre nosso trabalho clínico e sobre a questão da psicanálise dita extramuros.

Freud (1920/1976) recebeu, em seu consultório, uma jovem, levada pelos pais, que estavam tristes e preocupados com o fato de a filha estar apaixonada por uma mulher mais velha e por ter, diante da recusa de seu amor, tentado o suicídio. Freud escuta o caso, tenta desvelar a trama familiar e amorosa que está aí em jogo e se questiona sobre a possibilidade e a necessidade de iniciar um processo psicanalítico a partir daí. Pondera o autor: será que é disso mesmo que a jovem precisa? Será que a psicanálise poderá ajudar essa jovem? Será que a homossexualidade é algo a ser curado? Seria a tentativa de suicídio um apelo? Uma tentativa de fazer valer o seu desejo? Qual seria a função do psicanalista diante dessa construção familiar? Abrir um processo analítico com a jovem e tentar desvelar os sentidos inconscientes de seu amor homossexual, ou de sua tentativa de suicídio? Ou inscrever cada um desses personagens na construção do caso e fazêlos, a partir daí, refletir sobre seus lugares e responsabilidades?

O que queremos destacar aqui é a posição freudiana de se abrir, mesmo no contexto de seu consultório, para a possibilidade de nem sempre, diante de um pedido de ajuda, dar início a um processo analítico, mas ter a clareza de que, em algumas ocasiões, e diante de determinados pacientes, podemos ser psicanalistas que fazem alguma outra coisa.

Winnicott (1962/1982), anos depois, retoma essa questão. Segundo sua perspectiva, a psicanálise não é para todos, e nem para todos os momentos. Em sua opinião, psicanálise é para quem necessita, deseja e pode suportá-la. Com isso, acreditamos que o autor, tal como Freud, procura incluir a possibilidade de pensarmos sobre o nosso trabalho a partir de um referencial não exclusivamente ortodoxo, no qual apenas o clássico trabalho analítico é importante e designativo de um psicanalista. Algumas vezes trabalhamos de uma outra forma, até mesmo para tornar um trabalho analítico possível, sem que isso nos desloque do nosso ofício e sem que isso faça com que deixemos de ser psicanalistas.

Para sustentar e justificar nosso posicionamento partimos de duas de nossas experiências profissionais com o trabalho clínico em contextos específicos e diferenciados: a clínica-escola de uma universidade e o ambulatório de um hospital geral. Neles destacaremos o modo pelo qual fomos encaminhando nosso trabalho durante um longo período preparatório, sem muita clareza e certeza sobre o que fazíamos, porém com plena convicção de que era isso que nossos pacientes necessitavam no momento. $\mathrm{O}$ fato de, nos desdobramentos, terem embarcado conosco na viagem da psicanálise foi apenas um feliz acontecimento, mas não a razão de nossos objetivos. $^{1}$

\section{Corredor, escada, árvore e formigas: quando sua sala de atendimento é um parque lá de fora}

Lucas chegou para atendimento no antigo CIAP-PUC-Rio com várias queixas: hiperativo, desatento, impulsivo, agressivo, não aprendia a ler e a escrever, batia, mordia... Os gritos lá fora eram ouvidos por qualquer pessoa 
que passasse pelo campus da PUC. Ele vinha sempre arrastado, empurrado, levado aos trancos e barrancos pela mãe, exausta, porque, apesar de ter somente 4 anos, Lucas era muito grande para sua idade e igualmente muito forte e pesado. Do estacionamento até a casa de atendimento da PUC, onde eu trabalhava enquanto fazia meu doutoramento nessa instituição, a cena se repetia toda semana. Chegava molhado, suado, xingando e berrando, forma de me dizer que estava lutando contra alguma coisa que doía muito dentro dele, forma de me perguntar: você resiste ou vai desistir de mim como todos os colégios dos quais fui expulso? Você aguentará tudo isso ou vai me odiar? Para atendê-lo, já que ele não ficava na sala 2 nem por dez minutos, fui tentando estabelecer algum ritmo e limite de outras formas: ele gostava de mim (havia me dito isso), gostava da PUC e de seu parque, mas não gostava de muitas coisas, e como ninguém dava conta de seus movimentos muitas vezes sem contenção, acabava fazendo o que queria ou, se fizesse algum esforço, ganhava o que queria depois, como bala, brinquedo, figurinha...

Recorri aqui a Winnicott e a seus conceitos de placement e management. Lucas me pedia um manejo totalmente diferenciado e um lugar onde ele pudesse realmente ser aceito como estava naquele momento.

Comecei quebrando a sessão, ou seja, ela não começava com sua entrada na sala. Quando eu ouvia os gritos lá de dentro, descia as escadas, andava até perto do estacionamento e esperava que ele chegasse. Abaixava-me e começava a tentar falar com ele. Assim ele ia se acalmando e parava de se debater. Depois íamos de mãos dadas (regra que impus para que ele, correndo, não fugisse e pudesse ser atropelado ou machucado pelos carros que entram no estacionamento dos professores da PUC) até a escada da casa, e lá sentávamos, e ele sempre trazia alguma coisa para me mostrar, folhas, bichinhos, pedrinhas... Depois íamos até a minha sala e brincávamos com o que ele tinha trazido ou com alguns brinquedos que eu tinha na caixa de xerox forrada que era a marca do meu consultório; a sala podia mudar, mas meu consultório estaria lá, como diziam as crianças.

Um dia Lucas chegou, e não chegou gritando. Agitado, quis entrar direto para a sala. Perguntei o que havia acontecido para ele estar com o semblante tão irritado. Ele gritou: - NADA!!!!!!!!! Chutou muita coisa que encontrou na sala, e eu lhe disse: -Parece que você está com muita raiva, e por isso chuta tudo por aqui, mas olha o que combinamos: você pode chutar o que quiser, mas não pode se machucar nem me machucar. Silêncio e chutes como resposta. De repente, ele abriu a porta da sala e saiu correndo pelo corredor que nem um foguete, e fui atrás dele. O que o parou foi meu grito: - PARA LUCASSSSSSSSSSSSSSSSS!!!!!!! Ele chegara na escada, descera, e temi por ele; parou perto de uma árvore imensa na frente da casa e ficou por lá, e fiquei na beira dessa floresta esperando... Ele batia com os pés no chão e gritava: - NÃO!! NÃO!!! NÃO!!!! Fui até ele e perguntei: - Com quem você está falando? Ele me disse: - Com as formigas, claro! Quer uma para você? Morro de medo de insetos, mas diante daquele momento, arrisquei meu medo e disse: - Tá bom... Formigas saúvas foram colocadas em folhas e dadas a mim... Aí decidi que iríamos falar sobre as formigas e sobre suas famílias e formigueiros... Perguntei: - Você bate com os pés no chão e grita porque as formigas estão lá no fundo e não te ouvem? Ele balançou a cabeça dizendo que sim. Nesse momento, 
ele me conta que as formigas tinham mãe e pai, que a mãe dessas formigas gritava e berrava muito, chorava, também, e que o pai das formigas saía muito cedo e gritava quando saía e acordava todo mundo, que era um barulhão só. Pergunto então a ele: - Será, Lucas, que você está querendo me dizer que é preciso fazer muito barulho com os pés, com as mãos, com os gritos bem altos para ver se o pai formiga e se a mãe formiga saem de dentro do formigueiro e venham ver o que está acontecendo aqui fora porque senão eles nem notam? Lucas parou de bater os pés, sentou no meio das formigas e das folhas, e sentei junto rezando para que esses insetos não nos machucassem; deitou em meu colo; o calor de fora nos fez ficar suados, e disse: - É, sim. Por quatro ou seis segundos, Lucas ficou assim, depois pulou rápido e me disse: - Vamos pra dentro fazer uma casa para nossas formigas? Subimos as escadas, entramos sem bater os pés no corredor e fomos para a sala... Essa cena aconteceu muitas e muitas vezes; se eu for contar quantas sessões tive fora de minha sala de atendimento, poderia dizer que o campus da PUC foi o lugar eleito por Lucas para poder ir se organizando e contando, com pedrinhas, formigas, aranhas e folhas, sua história imersa em gritos, e não em olhares para o que ele realmente precisava: contenção e alguém que sobrevivesse à tempestade e ao furacão ambulante em que ele se transformava quando sentia no ar que talvez alguém pudesse abandoná-lo.

\section{Uma vista para o mar, montanhas e uma ponte: quando o ambulatório hospitalar se desloca para a varanda}

A primeira vez em que me encontrei com Luciana, já houve algo de inusitado e diferente. Era uma das primeiras pacientes que eu recebia no ambulatório hospitalar depois de anos de prática clínica desenvolvida em meu consultório particular. Eu a esperava na salinha da seção de psicologia reservada para os atendimentos individuais, e ela estava um pouco atrasada. A chefe da seção passou pela porta e me disse: - Você está esperando sua paciente aí, sentadinha? Aqui não é seu consultório não, doutora, vai buscar sua paciente. Se ela não estiver na sala de espera, procura no jardim, no pátio, enfim, circula por aí. Impactada com a surpresa, fui procurá-la. Ela estava na sala de espera e achou que eu fosse médica (surpresa novamente), e disse ter vindo para ser medicada (mais uma surpresa). Com tantas surpresas, iniciei esse atendimento sem nenhuma certeza sobre o modo como deveria conduzi-lo.

Luciana havia sido encaminhada pela clínica de reumatologia do hospital com sintomas precisos: dores nas pernas que a impediam de caminhar. O diagnóstico de uma doença reumatológica rara colocava por terra a possibilidade de entendermos que esse sintoma possui um significado simbólico que sustentasse seu entendimento como sintoma de uma conversão histérica. Porém, se a hipótese diagnóstica sobre o fato de tratarse de uma conversão histérica não podia ser consolidada em sua totalidade, investi em minhas suspeitas de que não devemos marcar a distinção orgânico/psíquico com tanta clareza, mas que devemos, como Freud o fez, perceber que há um emaranhado entre os dois, uma trama que torna os limites entre ambos embaçados, intrincados, entrelaçados, impossíveis de se precisar. Creio que seja a isso que Freud (1895/1976) fazia referência ao apelar para a equação etiológica das neuroses, que se iniciava na organização somática (hereditariedade) e se 
fundia nas causas necessárias (sexualidade), nas causas concorrentes (fatiga, doenças orgânicas, perdas afetivas, etc.) e, por fim, nas causas precipitantes (acontecimentos cotidianos, experiências e vivências banais). Em outras palavras, o autor nos chamou a atenção para o fato de que não é qualquer parte do corpo que se presta à construção de um sintoma histérico, mas que, para isso, é necessário haver uma complacência somática, ou seja, um lugar no corpo que se presta à conversão (Freud, 1905 [1901]/1976).

Assim, arrisquei pensar que, para além da organização orgânica de seus sintomas, haveria algo a ser decifrado e trabalhado em nosso espaço clínico. E assim o fiz. Mas Luciana parecia querer contradizer minhas expectativas. Ela, constantemente, me retirava do setting, me demandava outras coisas, me fazia, literalmente, sair da minha salinha para encontrá-la em outros lugares e falar com outros personagens. Uma vez não veio à sessão, mas enviou o marido para que ele me dissesse como ela estava e perguntasse o que ela deveria fazer para melhorar!! Outra vez chamaram-me na reumatologia, porque ela tinha que fazer um exame e afirmava que só o faria se eu estivesse presente, ao seu lado. E estive com ela durante todo o procedimento. Em outra oportunidade, recebeu o resultado de um exame e o trouxe para a sessão para abri-lo em minha presença. Lemos juntas o resultado. Em todas essas ocasiões, eu tinha a nítida sensação de que estava fazendo alguma outra coisa, mas não psicanálise. A impressão que eu tinha era que Luciana me pedia, demandava, e frequentemente conseguia, transformar suas sessões em momentos de acompanhamento, suporte, contenção, sustentação, etc, momentos que em nada se assemelhavam ao trabalho psicanalítico que eu estava acostumada a desenvolver no consultório, trabalho de livre-associação, que lança o paciente à recordação de experiências e vivências infantis esquecidas, à proposição de reflexões sobre o Édipo, inscritas no campo da transferência no plano simbólico. Ao contrário, o trabalho que desenvolvia com Luciana era de outra ordem. Sem mediações, sem matizes, puro, direto, vivo.

Mas... algo começou a se modificar em um dia especial. Cheguei ao ambulatório para atendê-la e nova surpresa me aguardava. Minha sala estava ocupada. O chefe da seção da neurologia estava atendendo em minha sala, porque a dele estava sendo consertada pelo pessoal de manutenção. Sem sala disponível, ele resolvera ocupar minha salinha. A princípio, fiquei muito brava, mas fui convencida por minha chefe de que não deveríamos iniciar uma briga com os médicos, um confronto direto que em nada nos favoreceria, e que deveríamos lidar com a situação de uma outra forma, fazer uma reclamação formal, encaminhá-la ao chefe do setor, etc, etc. E me disse: - Quando isso ocorre e ficamos sem sala para atender, a gente atende na varanda; já coloquei duas cadeiras pra vocês, você pode atendê-la lá? Vacilante, concordei, e fui buscar Luciana na sala de espera; expliquei a situação e nos encaminhamos para a varanda. Nova surpresa: a vista era MARAVILHOSA! De lá víamos a baía, o mar aberto ao longe, o céu azul, alguns barcos, embarcações, as montanhas, e a ponte Rio-Niterói. Ficamos as duas em silêncio por alguns instantes, e Luciana começou a comentar sobre a vista, a paisagem, os movimentos e, por fim, sobre a ponte que liga as duas cidades, que liga pessoas, que a fez lembrar quando era criança e ia a Niterói visitar parentes da família da mãe, das sensações de infância, 
da relação com a mãe, tão conturbada, tão difícil, tão violenta em alguns momentos e tão distante em outros. Da sensação de afastamento, de abandono, de desamparo, de não pertencimento a essa família, a essa mãe. De como muitas vezes duvidou ser mesmo filha dessa mulher tão diferente dela, tão ríspida, tão pouco afetiva. Mas, ao mesmo tempo, sabia que era filha dela, porque em uma coisa eram iguais: nas dores das pernas. Tinha puxado isso da mãe, tinham a mesma doença. E ainda que a mãe duvidasse, Luciana, às vezes, Ihe dizia: - Não adianta, mãe, achar que eu não sou sua filha, as dores nas pernas não enganam, sou sua filha. Nesse instante, olha-me espantada e diz: - Nossa, que estranho isso, né? Por que que eu preciso dessas dores pra ter certeza de que sou filha dela? E eu respondo: - É, é realmente interessante. Creio que a gente poderá entender melhor tudo isso; faleme mais um pouco sobre sua mãe, suas lembranças, suas sensações... e olhamos, novamente, para o mar... as montanhas... a ponte...

\section{Por que sermos analistas fazendo outra coisa: o lugar do setting em clínicas denominadas extramuros}

Apresentamos dois pequenos relatos de nossa clínica em contextos denominados extramuros com o propósito de tomá-los como ponto de partida e de fundamento para suscitarmos algumas reflexões a respeito daquilo que entendermos por setting na clínica psicanalítica.

Embora os dois exemplos se refiram a contextos diferentes (universidade e hospital), acreditamos que haja algo em comum entre eles e que em ambos podemos perceber de forma clara a metáfora da viagem efetuada por Freud para designar o trabalho clínico da psicanálise em ação, em produção, em acontecimento. Em ambos os exemplos, pudemos perceber todo um movimento inaugural que antecede, prepara e torna possível algo da psicanálise se iniciar e se processar. Nesses momentos iniciais, vimos nosso trabalho sendo questionado, pressionado, colocado em xeque; nesses momentos, as ocorrências pareciam indicar a impossibilidade de se psicanalisar nesses contextos, que nos demandavam uma posição diferente daquela que nós nos acostumáramos a supor que seria a de um psicanalista, contextos que exigiram de nós a aceitação de uma postura diferenciada no sentido de assumirmos, a partir do referencial da psicanálise, um lugar de escuta, de contenção, de organização, de diálogo com outros profissionais, com outros personagens da vida do paciente, com seus amigos, parentes, filhos, etc. Por se tratar de um posicionamento diferenciado, concordamos com Winnicott (1962/1982, p.155) quando ele afirma que, nesses momentos, somos "psicanalistas praticando outra coisa que acreditamos ser apropriada para a ocasião". Mas acreditamos que seja a partir daí que, em algumas ocasiões, em alguns casos, conseguimos abrir as portas para o trabalho da psicanálise propriamente dito, e, como nos indicou Freud (1920/1976), embarcarmos com o paciente na viagem da psicanálise.

Gostaríamos de deixar claro que, em nossa experiência, não foi com todos os pacientes que um processo analítico pôde ser iniciado. Em um grande número dos atendimentos, ficamos nos preparativos, ou porque o paciente interrompeu o tratamento, ou porque os pais decidiram interrompêlo ou decidiram procurar outro tipo de tratamento, ou porque, nós, por nossas 
Nunca se pode dizer até onde esse caminho nos levará; cedese primeiro em palavras e depois, pouco a pouco, em substância também" (Freud, 1921, p. 117). próprias resistências, não conseguimos dar prosseguimento ao trabalho. Porém, o fato de nem todos os pacientes terem embarcado na psicanálise não nos parece motivo suficiente para não tentá-la sempre, pois, se tomarmos a perspectiva da psicanálise, não há subjetividade sem divisão, não há sujeito sem conflito, não há sofrimento humano que se organize a partir de uma lógica simplista e direta que não leve em conta a existência do Inconsciente. Como nos informa Winnicott (1959/1982, p.125):

No caso de qualquer indivíduo, há três coisas: em um extremo, há a hereditariedade; no outro extremo há um ambiente que apóia ou falha e traumatiza, e no meio está o indivíduo vivendo, se defendendo e crescendo. Em psicanálise nos ocupamos do indivíduo vivendo, se defendendo e crescendo

Apostar nesse saber e nessa perspectiva nos parece ser a direção a ser seguida, o que nos obriga, em termos de setting e de manejo, a partir de uma lógica igualmente complexa que nos permita alargar nossos horizontes de forma a não restringi-los em relação ao lugar (as quatro paredes de um consultório) ou a regras técnicas (número de sessões semanais, uso do divã, pagamento, etc), mas praticá-la a partir de uma ética que a sustente em sua complexidade (Pinheiro, 2003).

Acreditamos que seja a isso que se refere o exemplo freudiano com o qual iniciamos nossa apresentação. Até mesmo dentro de seu consultório, Freud nos fornece um belo exemplo sobre os preparativos de uma análise que poderá vir-a-ser, ou não. E em nada vemos o autor questionar a validade e a adequação de seu trabalho nesse contexto.

É interessante, portanto, que notemos que Freud (1912/1976; 1913/1976;
1915[1914]/1976) tenha sido, em seus artigos sobre a técnica, bastante flexível, ao afirmar que cada analista deveria encontrar o seu modo próprio de atuar, indicando que suas orientações seriam apenas recomendações, e não leis que governam a clínica. Em suas palavras:

Penso estar sendo prudente, contudo, em chamar essas regras de recomendações e de não reivindicar qualquer aceitação incondicional a elas. A extraordinária diversidade das constelações psíquicas envolvidas, a plasticidade de todos os processos mentais e a riqueza dos fatores determinantes opõem-se a qualquer mecanização da técnica (Freud, 1913, p. 164).

No entanto, em contraste com essa flexibilidade técnica, encontramos em sua obra um autor extremamente rigoroso em termos de teoria, e várias vezes o vemos sustentar seus argumentos sem ceder um milímetro em suas posições metapsicológicas. Encontramos exemplos claros desse posicionamento ao longo de sua obra quando Freud até mesmo rompe com alguns de seus discípulos mais diletos e importantes por discordâncias teóricas, como Jung, por exemplo (Gay, 1989). Igualmente, muitas vezes alguns discípulos e leitores insinuaram que seria mais prudente mudar alguns termos da psicanálise para que ela fosse socialmente aceita com mais facilidade, como, por exemplo, utilizar erótico ou Eros no lugar de sexual ou sexualidade. A esses pedidos, sua resposta nos indica a direção exata de seu posicionamento: "Não quis fazê-lo, porque me apraz evitar fazer concessões à pusilanimidade. Nunca se pode dizer até onde esse caminho nos levará; cedese primeiro em palavras e depois, pouco a pouco, em substância também" (Freud, 1921, p. 117). 
Por essas razões, acreditamos tratar-se, em psicanálise, de um posicionamento ético, e não técnico. Talvez sejam essas as razões que permitiram que Freud, em muitas ocasiões, deixasse o conforto de seu consultório para efetuar sessões de análise com seus pacientes caminhando pelos parques e jardins ensolarados ou estrelados de Viena. Foi assim com Ferenczi, e foi assim, principalmente, com Eitingon (Gay, 1989).

Acreditamos que, a esse posicionamento freudiano, fundamentalmente criativo, Winnicott tenha dado continuidade e sustentação abrindo espaço para uma atuação clínica ativa às necessidades de seus pacientes. Em um de seus textos, por exemplo, Winnicott (1962/1982) afirma ser fundamental para um tratamento que o analista se mantenha bem, desperto e, sobretudo, vivo. Vivo, para ele, significava que o analista deve sobreviver aos ataques agressivos de seus pacientes para que, com isso, possa ser constituído, neles, como um objeto subjetivo do qual poderão fazer uso próprio.

Em nossa opinião, no período que demarcamos como preparatório para a análise, o analista é constantemente testado pelos pacientes, e acreditamos que a instauração da análise dependerá, em grande parte, de sua possibilidade de sobreviver aos ataques destrutivos quer sejam provenientes do paciente, quer sejam de seus familiares ou dos atores institucionais.

É nesse sentido que, para Winnicott, devemos, a cada novo paciente, responder às suas necessidades básicas como a mãe suficientemente boa deveria responder: adaptando-se ativamente. Em suas palavras:
"Descobri que o paciente necessita de fases de regressão à dependência dentro da transferência, resultando em experiências do efeito total da adaptação à necessidade que, na verdade, se baseia na capacidade do analista (a mãe) de identificar-se com seu paciente (seu bebê) " (Winnicott, 1963a/1982, p. 226).

Para o autor, o mais triste para um bebê, em seus primeiros momentos de vida, é depararse com uma mãe deprimida que responde às suas necessidades de forma automática, sem libido, sem desejo, sem vida, deixando ao bebê a quase impossível tarefa de se constituir como um sujeito desejante a partir daí. O perigo é que, segundo o que nos informa André (2009), como analistas, podemos nos esconder atrás de uma falsa noção de objetividade ou de neutralidade e responder às necessidades vitais de nossos pacientes desse lugar morto e fazê-los reviver a experiência da mãe-morta que em nada auxilia o seu caminhar.

A perspectiva winnicottiana ao contrário, nos informa que tanto a mãe quanto o analista facilitariam o desenvolvimento de seu bebê/ paciente se pudessem responder de uma forma ativa e viva às suas necessidades. Acreditamos, assim, que a ocorrência de uma adaptação ativa às necessidades do paciente depende da possibilidade do analista em se abrir ao inusitado, como nos exemplos clínicos que apresentamos.

Para concluir (por enquanto), os trabalhos de Freud e de Winnicott parecem indicar que a questão referente ao setting na psicanálise se relaciona muito mais com o campo teórico que embasa nossas concepções sobre o ser humano, sua construção como sujeito desejante, vivo, na tarefa incessante de se relacionar com o mundo do que com o lugar 
em que nosso trabalho de desenvolve. Os lugares serão apenas suportes materiais para que uma outra cena se inaugure, uma outra narrativa seja possível, uma outra história possa ser contada.

Enfim, a partir do trabalho desses dois psicanalistas genuínos e criativos, gostaríamos de deixar para reflexão uma pergunta sobre a psicanálise extramuros: quem foi mesmo que construiu os muros? Pois, em essência, em uma análise:

Você se dedica ao seu caso.

Você aprende a saber como é se sentir como seu cliente.

Você se torna digno da confiança para o campo limitado de sua responsabilidade profissional.
Você se comporta profissionalmente.

Você se preocupa com o problema de seu cliente.

Você aceita ficar na posição de um objeto subjetivo na vida do cliente, ao mesmo tempo em que conserva os pés na terra.

Você aceita amor, e mesmo o estado de enamorado, sem recuar e sem representar sua resposta.

Você aceita ódio e o recebe com firmeza, em vez de recebê-lo com vingança.

Você tolera em seu cliente a falta de lógica, de inconsistência, suspeita, confusão, debilidade, mesquinhez, etc, e reconhece todas essas coisas desagradáveis como sintomas de seu sofrimento (Winnicott,1963b/1882, p. 205). 
Maria Vitória Campos Mamede Maia

Mestre e Doutora pela Pontifícia Universidade Católica do Rio de Janeiro, Professora Adjunta da Universidade Federal do Rio de Janeiro, RJ - Brasil.

E-mail: mariavitoriamaia@gmail.com

\section{Nadja Nara Barbosa Pinheiro}

Mestre em Psicologia pela Universidade Federal do Rio de Janeiro e Doutora em Psicologia pela Pontifícia

Universidade Católica do Rio de Janeiro, Professora Adjunta III no Departamento de Psicologia da Universidade

Federal do Paraná, Paraná - PR - Brasil.

E-mail: nadjanbp@ufpr.br

\section{Endereço para envio de correspondência:}

Rua Padre Ildefonso, 230/1701; Batel, Curitiba. CEP: 80240-160.

Recebido 26/9/2009, 1a Reformulação 25/1/2011, Aprovado 31/3/2011. 


\section{Referências}

André, J. (2008). Laura ou os confins sexuais da necessidade. Estudos de Psicanálise, 31(1), 64 - 75.

Freud, S. (1976). Resposta às críticas a meu artigo sobre a neurose de angústia. In Edição standard brasileira das obras psicológicas completas de Sigmund Freud (J. Salomão, trad., Vol. 3, pp. 121-140). Rio de Janeiro: Imago (Trabalho original publicado em 1895)

Freud, S. (1976). Fragmentos da análise de um caso de histeria. In Edição standard brasileira das obras psicológicas completas de Sigmund Freud (J. Salomão, trad., Vol. 7, pp. 123-242). Rio de Janeiro: Imago (Trabalho original publicado em 1904).

Freud, S. (1976). Recomendações aos médicos que exercem a psicanálise. In Edição standard brasileira das obras psicológicas completas de Sigmund Freud (J. Salomão, trad., Vol. 12, pp. 147-162). Rio de Janeiro: Imago (Trabalho original publicada em 1912).

Freud, S. (1976). Sobre o início do tratamento. (Novas recomendações aos médicos que exercem a psicanálise I). In Edição standard brasileira das obras psicológicas completas de Sigmund Freud (J. Salomão, trad., Vol. 12, pp. 163-190). Rio de Janeiro: Imago (Trabalho original publicado em 1913).

Freud, S. (1976). Recordar, repetir e elaborar (Novas recomendações aos médicos que exercem a psicanálise II). In Edição standard brasileira das obras psicológicas completas de Sigmund Freud (J. Salomão, trad., Vol. 12, pp. 191-206) Rio de Janeiro: Imago (Trabalho original publicado em 1914).

Freud, S. (1976). Observações sobre o amor transferencial (Novas recomendações aos médicos que exercem a psicanálise III). In Edição standard brasileira das obras psicológicas completas de Sigmund Freud (J. Salomão, trad., Vol. 12, pp. 207-221) Rio de Janeiro: Imago (Trabalho original publicado em 1915).

Freud, S. (1976). A psicogênese de um caso de homossexualismo numa mulher. In Edição standard brasileira das obras psicológicas completas de Sigmund Freud (J. Salomão, trad.,
Vol. 18, pp. 183-214). Rio de Janeiro: Imago (Trabalho original publicado em 1920).

Freud, S. (1976). Psicologia de grupo e a análise do ego. In Edição standard brasileira das obras psicológicas completas de Sigmund Freud (J. Salomão, trad., Vol. 18, pp. 89-182). Rio de Janeiro: Imago (Trabalho original publicado em 1921).

Gay, P. (1989). Freud: uma vida para nosso tempo. São Paulo: Companhia das Letras.

Pinheiro, N. (2003). Uma casa com paredes de cristal: a clínica psicanalítica no ambulatório hospitalar. Tese de doutorado, Instituto de Psicologia, Pontifícia Universidade Católica do Rio de Janeiro, Rio de Janeiro.

Winnicott, D. (1982). Classificação: existe uma contribuição psicanalítica à classificação psiquiátrica? In D. Winnicott, O ambiente e os processos de maturação: estudos sobre a teoria do desenvolvimento emocional (I. Ortiz, trad., pp. 114-127). Porto Alegre: Artes Médicas (Trabalho original publicado em 1959).

Winnicott, D. (1982). Os objetivos do tratamento psicanalítico. In D. Winnicott, O ambiente e os processos de maturação: estudos sobre a teoria do desenvolvimento emocional (I. Ortiz, trad., pp.152-155). Porto Alegre: Artes Médicas (Trabalho original publicado em 1962).

Winnicott, D. (1982). Dependência no cuidado do lactente, no cuidado da criança e na situação analítica. In D. Winnicott, $O$ ambiente e os processos de maturação: estudos sobre a teoria do desenvolvimento emocional (I. Ortiz, trad., pp. 225-233). Porto Alegre: Artes Médicas (Trabalho original publicado em 1963a)

Winnicott, D. (1982). Os doentes mentais na prática clínica. In D. Winnicott, O ambiente e os processos de maturação: estudos sobre a teoria do desenvolvimento emocional (I. Ortiz, trad., pp. 196-206). Porto Alegre: Artes Médicas (Trabalho original publicada em 1963b). 